\title{
Avaliação do eixo hipotalâmico-hipofisário-tireoidiano em crianças com síndrome de Down
}

\author{
Evaluation of the hypothalamic-pituitary-thyroid axis in children with Down syndrome
}

\author{
Ana Tereza de A. Oliveira ${ }^{1}$, Carlos A. Longui ${ }^{2}$, Luis Eduardo P. Calliari ${ }^{3}$, \\ Eduardo de A. Ferone ${ }^{4}$, Fábio S. Kawaguti ${ }^{5}$, Osmar Monte ${ }^{6}$
}

\section{Resumo}

Objetivo: determinar a secreção de TSH em crianças com síndrome de Down, sem quadro clínico-laboratorial clássico de hipotireoidismo.

Métodos: analisou-se 14 crianças com síndrome de Down e idade média de 3,4 $( \pm 1,8)$ anos. Excluiu-se pacientes com sintomas clássicos de hipotireoidismo ou hipertireoidismo, ou que apresentassem anticorpos antitireóide positivos. Os pacientes foram comparados a um grupo controle de 16 pacientes com idade média de 11,8 $( \pm 3,8)$ anos e diagnóstico de baixa estatura familial ou atraso constitucional do crescimento. Foram determinadas as concentrações de TSH, T3, T4, T4L e prolactina no tempo basal e após estímulo com TRH. Pacientes com síndrome de Down, subdivididos quanto ao TSH basal, foram comparados em relação às concentrações basais de T3, T4, T4L e prolactina.

Resultados: os valores basais de TSH e de prolactina foram significativamente maiores no grupo com síndrome de Down. Após estímulo com TRH, o pico de TSH foi maior no grupo com síndrome de Down. Tanto o número de pacientes com TSH basal $>5 \mu \mathrm{U} / \mathrm{ml}$, quanto o número dos que apresentaram hiper-resposta ao estímulo com TRH (pico de TSH > $30 \mu \mathrm{U} / \mathrm{ml}$ ), foi maior no grupo com síndrome de Down.

Conclusões: freqüentemente, crianças portadoras de síndrome de Down apresentam elevação do TSH basal, mesmo na presença de valores basais normais de hormônios tireoidianos e anticorpos antitireóide negativos. A maioria dessas crianças $(65 \%)$ apresenta hiper-resposta ao teste de estímulo com TRH. Nossos achados demonstram que nem todas as crianças com síndrome de Down e TSH elevado apresentam quadro clássico de hipotireoidismo, sugerindo nesses pacientes uma secreção anômala de TSH de origem hipotalâmica.

J Pediatr (Rio J) 2002; 78 (4): 295-300: hipotireoidismo, síndrome de Down, TSH.

\begin{abstract}
Objective: to determine the thyroid stimulating hormone (TSH) secretion in children with Down syndrome (DS), who do not present clinical and laboratory evidence of classical hypothyroidism and concomitant undetectable antibodies.
\end{abstract}

Methods: fourteen children with DS with a mean age of 3.4 $( \pm 1.8)$ years were studied. Patients with classical hypothyroidism or hyperthyroidism or those with positive antithyroid antibodies were excluded. The DS group was compared to a control group of 16 children with a mean age of $11.8( \pm 3.8)$ years, diagnosed as having familial short stature or constitutional growth delay. Both groups underwent hormonal measurements at basal condition to determine serum TSH, T3, T4, free T4 and prolactin concentrations and after stimulation with thyrotropin releasing hormone (TRH). Thyroid hormones concentrations were also compared when children with DS were subdivided into two groups according to their basal TSH levels.

Results: basal TSH and prolactin levels were significantly higher in DS group. After stimulation with TRH, TSH peak was higher in the DS group. The number of patients presenting basal TSH levels higher than $5 \mu \mathrm{U} / \mathrm{mL}$ and TSH peaks higher than $30 \mu \mathrm{U} / \mathrm{mL}$ were significantly higher in the DS group.

Conclusions: children with Down syndrome present frequent increase in basal TSH concentrations, despite the presence of normal basal thyroid hormones levels and negative antithyroid antibodies. Most of them (65\%) show early intense response after TRH stimulation. Our data demonstrate that in spite of the absence of classic hypothyroidism and/or antithyroid antibodies, an abnormal pattern of TSH secretion occurred in patients with Down syndrome, possibly related to hypothalamic dysfunction.

J Pediatr (Rio J) 2002; 78 (4): 295-300: hypothyroidism, Down syndrome, TSH.

1. Residente de $4^{\circ}$ ano da Unidade de Endocrinologia Pediátrica, Dep. de Pediatria e Puericultura - Santa Casa de Misericórdia de São Paulo, DPP/SCMSP.

2. Professor Assistente da Unidade de Endocrinologia Pediátrica - DPP/SCMSP.

3. Professor Assistente da Unidade de Endocrinologia Pediátrica - DPP/SCMSP.

4. Quintanista da Faculdade de Ciências Médicas da Santa Casa da São Paulo.

5. Quintanista da Faculdade de Ciências Médicas da Santa Casa de São Paulo.

6. Chefe da Unidade de Endocrinologia Pediátrica - DPP/SCMSP

Artigo submetido em 08.01.02, aceito em 08.05.02. 


\section{Introdução}

O eixo hipotalâmico-hipofisário-tireoidiano (HHT) é parte importante do controle endócrino-metabólico, permitindo um ajuste fino às condições do meio ambiente e à oferta energética. Em crianças portadoras de síndrome de Down, é freqüente a observação de anormalidades da função tireoidiana, em especial a tireoidite de Hashimoto e as disgenesias tireoidianas ${ }^{1}$.

Os hormônios tireoidianos encerram funções importantes no sistema nervoso central (SNC). Estão envolvidos na migração e diferenciação neuronal, simpatogênese, síntese e secreção de neurotransmissores, mielinização, bem como na regulação da expressão de genes nas células neuronais ${ }^{2}$. A associação da deficiência de hormônios tireoidianos potencialmente agrava as alterações neurológicas observadas nos portadores de síndrome de Down.

Na dependência do nível em que a disfunção aparece, o hipotireoidismo pode ser classificado em primário (tireoidiana), secundário (hipofisária) ou terciário (hipotalâmica). O conceito de hipofunção do eixo HHT inclui um espectro de gravidade que varia desde a deficiência completa dos hormônios tireoidianos, determinando um quadro clínico clássico de hipotireoidismo, até um quadro mais leve, no qual T3 e T4 são normais às custas de maior pulsatilidade e amplitude de secreção do TSH. Desta forma, o hipotireoidismo primário pode ainda ser classificado em diferentes graus ${ }^{3}$, sendo que no grau 1 ocorrem sintomas clínicos, concentração reduzida de hormônios tireiodianos, valor basal de TSH elevado e hiper-resposta precoce ao teste de estímulo com TRH. No grau 2, os sinais e sintomas clínicos são discretos, a concentração de hormônios tireoidianos está normal, mas o TSH basal está elevado, também existindo uma hiper-resposta ao estímulo com TRH. No grau 3, os sinais e sintomas estão ausentes, a concentração de hormônios tireoidianos está normal, e o TSH basal está no limite superior do normal ou pouco elevado, havendo uma hiper-resposta ao teste de estímulo com TRH. Nesse último grupo, os pacientes que não apresentam bócio ou anticorpos antitireoidianos positivos podem não corresponder a um hipotireoidismo real, mas sim a indivíduos com anormalidades do SNC e liberação hipotalâmica anômala do TRH. O termo hipotireoidismo clínico está associado ao grau 1, enquanto o termo hipotireoidismo subclínico se refere aos graus 2 e 3 . Tais indivíduos com concentrações séricas normais de T4 e T3, mas com concentração sérica elevada de TSH, podem evoluir para o hipotireoidismo clássico, com concentrações progressivamente menores de T4 e T3, e elevação adicional de TSH. Outros podem permanecer com o quadro inalterado, ou mesmo normalizam o TSH durante o seguimento clínico ${ }^{4,5}$. Portanto, nem todo indivíduo que apresenta T4 e T3 normal e TSH elevado deve ser classificado como portador de hipotireoidismo subclínico, uma vez que o seguimento clínico longitudinal tem identificado pacientes que mantêm a função tireoidiana normal em longo prazo, aparentemente ajustada a uma concentração discretamente elevada de $\mathrm{TSH}^{6}$.
Com relação ao controle do eixo HHT, sabe-se que o TRH estimula a biossíntese, secreção e glicosilação do TSH, enquanto os hormônios tireoidianos atuam como inibidores da secreção do TSH, por bloquear a transcrição de seu gene, sendo, ainda, capazes de reduzir a secreção do TRH, bem como sua ação hipofisária.

A dopamina é uma catecolamina que atua tanto ao nível hipotalâmico quanto sobre os receptores tipo D2 dos tireotrófos hipofisários, inibindo a secreção de $\mathrm{TSH}^{7}$ e de prolactina. O TRH age como um estimulante de importância secundária na secreção de prolactina. Devido a essa semelhança entre os fatores controladores das secreções de TSH e prolactina, frequientemente ambos hormônios são quantificados quando da avaliação do eixo HHT. Desta forma, as anormalidades do eixo HHT em pacientes com síndrome de Down podem estar associadas a doenças primárias da tireóide ou a alterações da secreção do TSH, dependentes de um insuficiente controle dopaminérgico da secreção hipofisária.

Este estudo teve o objetivo de reconhecer a frequiência de alterações da regulação do eixo HHT em crianças com síndrome de Down que não apresentavam quadro clínico ou laboratorial característico de hipotireoidismo.

\section{Casuística e métodos}

Foram analisados 14 pacientes portadores de síndrome de Down (SD), acompanhados na unidade de endocrinologia pediátrica do Departamento de Pediatria e Puericultura da Santa Casa de Misericórdia de São Paulo, sendo nove do sexo masculino, e cinco do sexo feminino. A idade dos pacientes variou entre 1,2 e 6,5 anos (média $=3,4$ e DP $\pm 1,8)$.

Excluíram-se indivíduos com diagnóstico clínico e laboratorial clássico de hipotireoidismo ou hipertireoidismo, ou que apresentavam anticorpos antitireoperoxidase ou antitireoglobulina positivos, os quais pudessem alterar diretamente a função tireoidiana, mascarando possíveis alterações do eixo HHT características da SD.

O grupo controle foi constituído por dezesseis pacientes, oito do sexo masculino e oito do sexo feminino, que apresentavam baixa estatura, mas não eram deficientes de hormônio do crescimento $(\mathrm{GH})$ - resposta ao teste de tolerância à insulina com concentrações de GH superiores a $7 \mathrm{ng} / \mathrm{ml}$. Este grupo controle foi avaliado com teste combinado e quantificação de TSH, prolactina, GH e cortisol, segundo rotina de avaliação de pacientes com baixa estatura. O diagnóstico final dos pacientes deste grupo foi de baixa estatura familial ou de atraso constitucional do crescimento, que representam variantes da normalidade. Outras características deste grupo controle são idade cronológica variando entre 5,5 e 15,4 anos (média $=11,8$ e $\mathrm{DP} \pm 3,8$ ), e concentrações séricas basais normais de $\mathrm{T} 3, \mathrm{~T} 4$ e T4 livre. 
As concentrações séricas basais de T3, T4, T4L, prolactina, anticorpos antitireoperoxidase e antitireoglobulina foram determinadas através de radioimunoensaio.

O teste de estímulo com TRH foi realizado com a administração de $7 \mu \mathrm{g} / \mathrm{kg}$, E.V., em bolo, e coleta de sangue com 0, 20, 40, 60 e 90 minutos para dosagem de TSH e prolactina. As concentrações séricas de TSH foram medidas por ensaio imunorradiométrico (IRMA).

Os valores considerados normais para cada um dos hormônios avaliados em condições basais foram TSH: 0,3$5 \mu \mathrm{U} / \mathrm{ml}$ (Active ${ }^{\circledR}$ TSH IRMA DSL-5300, DSL, Inc. Texas, USA); T3: 80-215 ng/d (Active ${ }^{\circledR}$ Triiodothyronine (T3) RIA DSL-3100, DSL, Inc. Texas, USA); T4: 5-12 $\mu \mathrm{g} / \mathrm{dL}$ (Active ${ }^{\circledR}$ Thyroxine DSL-3200, DSL, Inc. Texas,USA); T4L: 0,8-2 ng/dL (Coat-a-Count ${ }^{\circledR}$ FreeT4, DPC ${ }^{\circledR}$, Los Angeles, USA); prolactina: 4,3-23,3 ng/dL (RIA-gnost ${ }^{\circledR}$ Prolactin, CIS bio international, France); anticorpo antitireoperoxidase: $<50 \mathrm{IU} / \mathrm{ml}$ (Anti-TMS Bridge, Biodata Diagnostics S.p.A., Roma, Italy) e anticorpo antitireoglobulina: < $100 \mathrm{IU} / \mathrm{ml}$ (Anti-HTG Bridge, BioChem ImmunoSystems Italia S.p.A., Diagnostics Division, Roma, Italy).

Para análise estatística dos resultados, empregou-se o programa SigmaStat for Windows versão 2.03, da SPSS Incorporation. Utilizou-se o teste t de Student ou o teste de Mann Whitney quando a distribuição das amostras era, respectivamente, paramétrica ou não paramétrica. Compararam-se as médias das concentrações basais de TSH, T3, $\mathrm{T} 4$, T4L e prolactina entre o grupo de indivíduos com SD e o grupo controle.

Compararam-se, ainda, as médias dos picos máximos de TSH obtidos após estímulo com TRH entre os dois grupos. Quanto à amplitude de resposta do TSH, considerou-se hiper-resposta ao TRH os picos de TSH superiores a $30 \mu \mathrm{U} / \mathrm{ml}$. A hiper-resposta foi considerada precoce quando o pico de TSH ocorreu entre 15-20 minutos, e tardia quando o valor de TSH entre 60-90 minutos foi superior ao valor observado entre 15-20 minutos do teste ${ }^{8}$.

Por fim, dividiu-se o grupo de pacientes com SD em dois subgrupos, um com TSH basal normal, e outro com TSH basal elevado (TSH basal $>5 \mu \mathrm{U} / \mathrm{ml}$ ), e comparou-se as médias das concentrações basais de T3, T4, T4L e prolactina entre eles.

Todos os procedimentos foram aprovados pelo Comitê de Etica em Pesquisa da Irmandade da Santa Casa de Misericórdia de São Paulo.

\section{Resultados}

As concentrações basais médias dos pacientes com SD e controles são mostradas na Tabela 1. Observa-se elevação significativa $(p=0,03)$ dos valores basais de TSH dos pacientes com $\mathrm{SD}$, média de 7,2 $\mu \mathrm{U} / \mathrm{ml}(\mathrm{DP} \pm 4,2)$ em relação à média do TSH do grupo controle. Entretanto, não são observadas diferenças significativas entre as médias de T3, T4 e T4L entre os dois grupos.
Tabela 1 - Concentrações séricas basais de TSH, T3, T4, T4L e prolactina (PRL) em pacientes com síndrome de Down $(n=14)$, e em controles $(n=16)$

\begin{tabular}{lccccc}
\hline & $\begin{array}{c}\text { TSH } \\
\boldsymbol{\mu U} / \mathbf{m l}\end{array}$ & $\begin{array}{c}\text { T3 } \\
\mathbf{n g} / \mathbf{d l}\end{array}$ & $\begin{array}{c}\mathbf{T 4} \\
\boldsymbol{\mu g} / \mathbf{d l}\end{array}$ & $\begin{array}{c}\text { T4L } \\
\mathbf{n g} / \mathbf{d l}\end{array}$ & $\begin{array}{c}\text { PRL } \\
\mathbf{n g} / \mathbf{d l}\end{array}$ \\
\hline SD & $7,2 \pm 4,2$ & $147 \pm 46$ & $9,8 \pm 2,1$ & $1,7 \pm 0,4$ & $13,1 \pm 5,5$ \\
Controle & $3,8 \pm 2,4$ & $162,3 \pm 57,7$ & $8,9 \pm 2,6$ & $1,3 \pm 04$ & $7,0 \pm 3,0$ \\
$\mathbf{p}$ & 0,03 & $\mathrm{~ns}$ & $\mathrm{~ns}$ & $\mathrm{~ns}$ & 0,017 \\
\hline
\end{tabular}

Os dados são expressos como médias \pm desvio-padrão. ns = não significativo.

Os valores basais de prolactina são significativamente menores $(p=0,017)$ no grupo controle, quando comparados aos observados nas crianças com SD.

A Tabela 2 descreve os resultados do teste de estímulo com TRH, e evidencia elevação significativamente maior $(\mathrm{p}=0,01)$ dos valores do pico de TSH observados nos indivíduos com SD, cuja média foi $37,3 \mu \mathrm{U} / \mathrm{ml}(\mathrm{DP} \pm 18,8$ ), em relação ao grupo controle, cuja média foi $20,2 \mu \mathrm{U} / \mathrm{ml}$ $(\mathrm{DP} \pm 8,8)$. Nos portadores de $\mathrm{SD}$, todos os pacientes que apresentaram hiper-resposta o fizeram de maneira precoce, ou seja, entre 15-20 minutos após o TRH. No grupo controle, apenas 2 pacientes apresentaram hiper-resposta durante o teste, um aos 20 minutos, e outro aos 30 minutos.

Além disso, a Tabela 2 mostra que o número de pacientes com TSH basal superior a $5 \mu \mathrm{U} / \mathrm{ml}$ no grupo com SD (nove de quatorze pacientes) é significativamente maior $(\mathrm{p}=0,03)$ que o observado no grupo controle, no qual apenas três de dezesseis pacientes apresentaram o TSH basal elevado. Observou-se, ainda, que o número de pacientes com SD e pico de TSH após TRH superior a $30 \mu \mathrm{U} / \mathrm{ml}$ (nove de quatorze pacientes) é significativamente maior $(\mathrm{p}=0,01)$ que o verificado para o grupo controle (dois de dezesseis pacientes).

Não ocorreu diferença do pico de prolactina após TRH entre grupo controle e SD.

A Figura 1 mostra a variação individual do TSH durante o teste de estímulo com TRH. Nos portadores de SD, observa-se que a maioria dos pacientes inicia o teste com TSH basal superior a $5 \mu \mathrm{U} / \mathrm{ml}$ e também a maioria atinge pico de TSH superior a $30 \mu \mathrm{U} / \mathrm{ml}$; neste grupo, dos nove pacientes com TSH basal superior a $5 \mu \mathrm{U} / \mathrm{ml}$, sete apresentaram hiper-resposta. Outros dois pacientes que não apresentavam TSH basal elevado também mostraram hiperresposta.

No grupo controle, a maioria dos pacientes apresenta um TSH basal normal e não atinge pico de TSH após TRH superior a $30 \mu \mathrm{U} / \mathrm{ml}$. Neste grupo, dos três indivíduos que apresentavam TSH basal superior a $5 \mu \mathrm{U} / \mathrm{ml}$, dois atingiram hiper-resposta.

A análise da Tabela 3, que compara as médias dos valores basais de T3, T4, T4L e prolactina entre os subgru- 
Tabela 2 - Resultados do TSH durante o teste de estímulo com TRH em pacientes com síndrome de Down $(n=14)$, e em controles $(n=16)$

\begin{tabular}{lcccc}
\hline & $\begin{array}{c}\text { TSH basal } \\
\boldsymbol{\mu U} / \mathbf{m L}\end{array}$ & $\begin{array}{c}\text { TSH } \\
\text { basal }>\mathbf{5} \boldsymbol{\mu} \mathbf{U} / \mathbf{m L}\end{array}$ & $\begin{array}{c}\text { TSH pico } \\
\boldsymbol{\mu} \mathbf{U} / \mathbf{m L}\end{array}$ & $\begin{array}{c}\text { TSH } \\
\text { pico }>\mathbf{3 0} \boldsymbol{\mu} \mathbf{U} / \mathbf{m L}\end{array}$ \\
\hline SD & $7,2 \pm 4,2$ & $9 / 14$ pacientes & $37,3 \pm 18,8$ & $9 / 14$ pacientes \\
Controle & $3,8 \pm 2,4$ & $3 / 16$ pacientes & $20,2 \pm 8,8$ & $2 / 16$ pacientes \\
$\mathbf{p}$ & 0,03 & 0,03 & 0,01 & 0,01
\end{tabular}

Os dados são expressos como médias \pm desvio-padrão ns $=$ não significativo.

pos de portadores de SD divididos quanto ao TSH basal, revela que não há diferença significativa dos hormônios tireoidianos e da prolactina entre o subgrupo de indivíduos com TSH basal normal e o subgrupo com TSH basal elevado.

\section{Discussão}

Nesse estudo, quando comparadas ao grupo controle, as crianças portadoras de SD apresentaram TSH elevado, mesmo na presença de valores basais normais de hormônios tireoidianos e anticorpos antitireoglobulina e antitireoperoxidase negativos. Além disso, observou-se que na maior parte dos pacientes com síndrome de Down (9/14 ou 65\%) existiu uma hiper-resposta de TSH durante o teste de estímulo com TRH.

Algumas hipóteses poderiam justificar os valores aumentados de TSH encontrados nestas crianças com SD, a saber:

1) os casos estudados podem representar indivíduos com hipotireoidismo primário inicial, ainda subclínico.

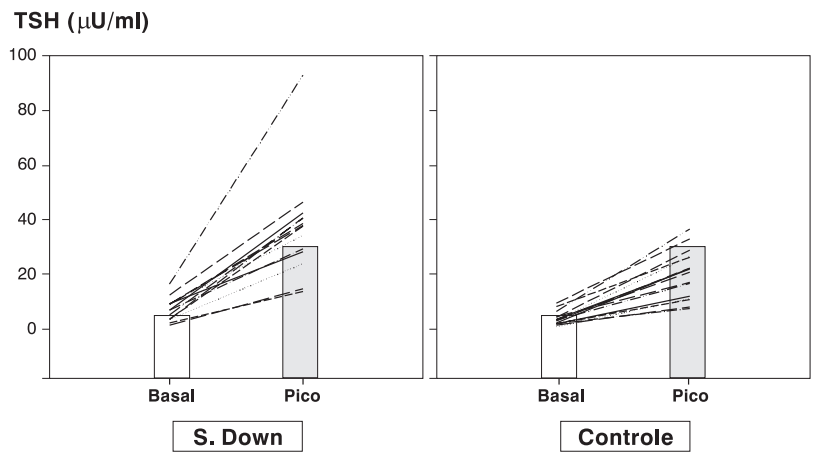

Figura 1 - Secreção individual de TSH durante o teste de estímulo com TRH $(7 \mu \mathrm{g} / \mathrm{kg})$ em pacientes com síndrome de Down, e em controles

Entretanto, algumas peculiaridades dos pacientes, notadas ao longo do acompanhamento ambulatorial mais prolongado, são contrárias a esta hipótese, como, por exemplo: os

Tabela 3 - Concentrações séricas basais de T3, T4, T4L e prolactina (PRL) em pacientes com síndrome de Down subdivididos quanto ao valor do TSH basal

\begin{tabular}{lccccc}
\hline & $\begin{array}{c}\text { TSH } \\
\boldsymbol{\mu U} / \mathbf{m L}\end{array}$ & $\begin{array}{c}\text { T3 } \\
\mathbf{n g} / \mathbf{d L}\end{array}$ & $\begin{array}{c}\mathbf{T 4} \\
\mathbf{\mu g} / \mathbf{d L}\end{array}$ & $\begin{array}{c}\mathbf{T 4 L} \\
\mathbf{n g} / \mathbf{d L}\end{array}$ & $\begin{array}{c}\text { PRL } \\
\mathbf{n g} / \mathbf{d L}\end{array}$ \\
\hline $\begin{array}{l}\text { TSH b<5 } \\
(\mathrm{n}=5)\end{array}$ & $3,0 \pm 0,9$ & $125,5 \pm 42,7$ & $9,3 \pm 0,9$ & $1,5 \pm 0,1$ & $12,15 \pm 5,27$ \\
$\begin{array}{l}\text { TSH b>5 } \\
(\mathrm{n}=9)\end{array}$ & $9,5 \pm 3,3$ & $158,9 \pm 45,6$ & $10 \pm 2,6$ & $1,7 \pm 0,6$ & $13,69 \pm 6,01$ \\
$\mathbf{p}$ & $\mathrm{ns}$ & $\mathrm{ns}$ & $\mathrm{ns}$ & $\mathrm{ns}$ & $\mathrm{ns}$ \\
\hline
\end{tabular}

Os dados são expressos como médias \pm desvio-padrão. ns $=$ não significativo. 
valores de $\mathrm{T} 3, \mathrm{~T} 4$ e $\mathrm{T} 4 \mathrm{~L}$ permanecem normais a longo prazo, juntamente com anticorpos antitireoglobulina e antitireoperoxidase, que se mantêm negativos; estas crianças apresentam estatura ajustada às curvas de crescimento da SD com percentil estável, e alguns casos tratados não apresentaram diferença clínica evidente quando comparados ao período pré-tratamento;

2) o TSH destes pacientes poderia apresentar certo grau de bioinatividade. Contudo, Konings et al. ${ }^{9}$ identificaram bioatividade normal do TSH em portadores de SD, a partir da dosagem de AMPc produzido por estímulo de receptores de TSH humanos expressos em células de ovário de hamster. A quantidade de AMPc obtida pelo estímulo dos receptores, com o uso in vitro do TSH dos portadores de SD, não foi significativamente diferente daquela obtida com o TSH de indivíduos controle não portadores da síndrome. Devese observar que as células do ovário de hamster foram transfectadas com gene humano, que codifica receptores de TSH de indivíduos normais, e não de portadores de SD;

3) os portadores de SD poderiam apresentar resistência tireoidiana ao nível dos receptores de TSH, ou mesmo um evento pós-receptor. Até o presente, nenhum estudo foi desenvolvido para comprovar esta hipótese;

4) como última hipótese, acreditamos ser possível uma diminuição do tônus dopaminérgico sobre o hipotálamo e a hipófise. Isso determinaria uma secreção aumentada do TSH, que associada a um fenômeno de down regulation dos receptores tireoidianos de TSH, proporcionaria valores basais normais de $\mathrm{T} 3$, T4 e T4L.

A elevação dos valores basais de prolactina observada no grupo de portadores de $\mathrm{SD}$ (média $=13,1 \mathrm{e} \mathrm{DP} \pm 5,5) \mathrm{em}$ relação à média do grupo controle $(\mathrm{p}=0,017)$ reforça esta hipótese. Apesar disso, não se observou diferença significativa entre os grupos de portadores de SD e controle quanto ao pico de prolactina durante o teste de estímulo com TRH. Ainda com relação ao teste do TRH, apesar da média dos valores de pico do TSH em portadores de SD ser significativamente maior que a média dos indivíduos do grupo controle (concordante com a hipótese do tônus dopaminérgico diminuído), os portadores de SD que apresentaram pico de TSH superior a $30 \mu \mathrm{U} / \mathrm{ml}$ responderam precocemente. A hiper-resposta de causa hipotalâmica, habitualmente descrita como tardia, não foi observada em nossos pacientes. Porém temos observado que a hiper-resposta precoce é também um achado freqüente em pacientes com deficiência de GH de origem hipotalâmica (dados não publicados).

Estudos prévios realizados em pacientes com SD reforçam a hipótese de menor secreção de dopamina no SNC, os quais relatam atrofia e diminuição do número de células produtoras de dopamina na substância negra da base do cérebro $^{10} \mathrm{e}$ área ventral tegmentar ${ }^{11,12}$. Esses achados são freqüentes em indivíduos com SD com mais de 40 anos, e se apresentam como uma demência semelhante à Doença de Alzheimer. Assim como a substância negra e a área ventral tegmentar (importantes áreas produtoras de dopamina no cérebro), os núcleos arqueados do hipotálamo (produtores da dopamina, que atua como hormônio inibitório sobre a secreção de TSH) também poderiam estar comprometidos.

Estudos sobre a indução de respostas por estímulos visuais, auditivos e somatosensoriais demonstraram que essas respostas apresentam amplitude maior em crianças com SD que em controles, com perda da característica redução da amplitude relacionada à idade, como observado nos controles, o que sugere deficiência de vias inibitórias na $\mathrm{SD}^{13}$, e fortalece a hipótese do tônus dopaminérgico deficiente.

Conclui-se que crianças portadoras de SD com frequiência apresentam elevação do TSH basal, mesmo na presença de valores basais normais de hormônios tireoidianos e ausência de auto-imunidade. Observou-se, ainda, que a maioria dessas crianças (65\%) apresentam hiper-resposta ao teste de estímulo com TRH. Esta conclusão sugere que haja uma disfunção hipotalâmica-hipofisária na secreção do TSH em pacientes com síndrome de Down, cuja causa permanece desconhecida.

Sendo assim, o pediatra deve ter cautela no acompanhamento de pacientes com SD com TSH elevado e T3, T4 normais. Não deve considerá-lo imediatamente como um portador de hipotireoidismo, sendo o acompanhamento clínico e laboratorial cuidadoso necessário para decidir quanto à necessidade $\mathrm{e}$ ao momento adequado de iniciar a reposição hormonal.

\section{Referências bibliográficas}

1. Karlsson B, Gustafsson J, Hedov G, Ivarsson SA, Annerén G. Thyroid dysfunction in Down's syndrome: relation to age and thyroid autoimmunity. Arch Dis Child 1998;79:242-5.

2. Bernal J, Nunez J. Thyroid hormones and brain development. Eur J Endocrinol 1995;133:390-8.

3. Sullivan PF, Wilson DA, Mulder RT, Joyce PR. The hypothalamicpituitary-thyroid axis in major depression. Acta Psychiatr Scand 1997;95:370-8.

4. Rubello D, Pozzan GB, Casara D, Girelli ME. Natural course of subclinical hypothyroidism in Down's syndrome: prospective study results and therapeutic considerations. J Endocrinol Invest 1995; 18:35-40.

5. Selikowitz M. A five year longitudinal study of thyroid function in children with Down syndrome. Dev Med Child Neurol 1993;35:396-401.

6. Kabadi UM, Cech R. Normal thyroxine and elevated thyrotropin concentrations: evolving hypothyroidism or persistent euthyroidism with reset thyrostat. J Endocrinol Invest 1997;20:319-26.

7. Wilber JF. Control of thyroid function: The hypothalamicpituitary-thyroid axis. In: Degroot LJ, Jameson JL, editores. Endocrinology. $3^{\mathrm{a}}$ ed. Philadelphia: Saunders; 1995. p.602-16.

8. Milner RDG, Herber SM. Response to TRH in suspected hypopituitarism. Arch Dis Child 1983;58:195-7. 
9. Konings GH, van Trotsenburg AS, Ris-Stalpers C, Vulsma T, Wiedijk BM, de Vijlder JJ. Plasma thyrotropin bioactivity in Down's syndrome children with subclinical hypothyroidism. Eur J Endocrinol 2001;144:1-4.

10. Yates CM, Simpson J, Gordon A, Maloney AF, Allison Y, Ritchie IM, et al. Catecholamines and cholinergic enzymes in pre-senile and senile Alzheimer-type dementia and Down's syndrome. Brain Res 1983;280:119-26.

11. Mann DM, Yates PO, Marcyniuk B. Dopaminergic neurotransmitter systems in Alzheimer's disease and in Down's syndrome at middle age. J Neurol Neurosurg Psychiatry 1987;50:341-4.

12. Godridge H, Reynolds GP, Czudek C, Calcutt NA, Benton M. Alzheimer-like neurotransmitter deficits in adult Down's syndrome brain tissue. J Neurol Neurosurg Psychiatry 1987;50:775-8
13. Dustman RE, Callner DA. Cortical evoked responses and response decrement in nonretarded and Down's syndrome individuals. Am J Ment Defic 1979;83:391-7.

Endereço para correspondência:

Dr. Carlos A. Longui

R. Cesário Mota Junior, 112 - Vila Buarque

CEP 01122-021 - São Paulo, SP

Fone/fax: (11) 3220.2008

E-mail: fisiolab@santacasasp.org.br 